ORIGINAL ARTICLE

\title{
Bone density at the os calcis: reference values, reproducibility, and effects of fracture history and physical activity
}

\author{
D J Chinn, J N Fordham, M S Kibirige, N J Crabtree, J Venables, J Bates, O Pitcher
}

Arch Dis Child 2005;90:30-35. doi: 10.1136/adc.2003.044578

See end of article for authors' affiliations

Correspondence to: Dr J N Fordham, The James Cook University Hospital, Marton Road, Middlesbrough TS4 3BW UK; John.Fordham@stees. nhs.uk

Accepted 22 April 2004

\begin{abstract}
Aims: To establish reference values for bone mineral density (BMD) measured at the os calcis (OC) in healthy UK Caucasian children. Secondary objectives were to assess the reproducibility of the measurement and the effects of fracture history and habitual physical activity.

Methods: A total of 403 children aged 5-18 were studied. Main outcome measures were: BMDOC measured by peripheral DXA, total BMD measured by whole body axial scanner, age, anthropometry, pubertal status, self-reported fracture history, and physical activity (PA) expressed as a three point score. Results: Complete data were available on 171 girls and 123 boys free of a history of fracture. BMDOC was related positively to age, body size, and total BMD, and could be predicted using a proportional model based on height alone ( $\mathrm{R}^{2}: 65 \%$ girls, $77 \%$ boys). Mean BMDOC appears to plateau in girls at 15 years and attain a value that concurs with the mean peak value in adult women. The $95 \%$ limits of agreement in repeated measures were -0.029 to $0.029 \mathrm{~g} / \mathrm{cm}^{2}(\mathrm{n}=53)$. Compared with sedentary children, those doing regular sports or PA for more than five hours a week had an increased BMDOC (by about $0.03 \mathrm{~g} / \mathrm{cm}^{2}$ or about $7 \%$ of the overall mean). A history of fracture $(\mathrm{n}=81)$ was associated with a reduced BMDOC in boys but not in girls, though our study may have been underpowered for a subgroup analysis. Conclusions: BMDOC can be measured easily and quickly in children older than 5 years and provides an objective measure of areal bone density for clinical and research studies using a reference range derived from its relation to height.
\end{abstract}

$\mathrm{B}$ one mass and density measurements in children have been used widely in genetic studies, ${ }^{12}$ growth studies, ${ }^{3-6}$ intervention trials, ${ }^{7-9}$ and clinical work. ${ }^{10}{ }^{11}$ In practice, the results are subject to difficulties in interpretation due to the effects of puberty on the skeleton with resultant changes in bone size affecting bone density measurements. ${ }^{12}$ Reference ranges for bone mineral content and density measured at axial sites have been established for children, ${ }^{13-15}$ even though there is no current consensus regarding the interpretation of such measurements. ${ }^{16}$ In adults the BMD os calcis (BMDoc) measured using peripheral densitometry has application in clinical practice, ${ }^{17} 18$ including prediction of fracture risk at the hip and forearm. ${ }^{19} 20$ The technique uses portable equipment and provides rapid measurement that could be an advantage in paediatric use. In childhood, the ossification centre of the os calcis becomes radiologically apparent at an average age of 7.6 years ( 5 th to 95th centile, 5.2-9.5 years) in boys and about 5.4 years ( 5 th to 95th centile, 3.5-7.3 years) in girls. ${ }^{21}$ The os calcis is a cancellous rich site with a ratio of cancellous to cortical bone of $95 / 5 .{ }^{22}$ In adults this has clinical relevance as in postmenopausal osteoporosis and steroid induced osteoporosis the predominant loss of bone is to the cancellous component, so the heel may represent a convenient window into the skeleton. However, despite the attractiveness of the methodology the role of peripheral densitometry in paediatric practice has not been clearly defined. ${ }^{23}$ One concern is the lack of reference data for the measurement, which is an areal density and so is related to body size. The principal aims of the study were to establish a predictive equation for BMDoc, to measure its precision, and to explore the inter-relation of it with the total body BMD, which reflects predominantly cortical bone. Secondary aims were to investigate the effects on BMDoc of fracture history and habitual physical activity.

\section{METHODS}

Healthy children aged 5-18 years were recruited from schools and community advertisements in Teesside. A research nurse visited schools to discuss the study and distributed information to the children. Later, and in the presence of a parent, a detailed explanation of the study was provided and consent obtained from the parent and child. Examinations were made in the hospital. Date of birth, ethnic origin, medical history, and details of medications were collected by questionnaire. Children were also rated on a three point physical activity (PA) score (little or no activity outside school, sports or PA at least 3 hours per week, sports regularly over 5 hours per week, for example in clubs). Height and body mass were measured and compared with UK growth reference ranges. ${ }^{24}$ Pubertal stage was determined by a trained nurse using photographs $^{25}$ to assess pubic hair, genitalia stage, and breast development, and a Prader orchidometer to assess testicular volume (self-reported). Children were classified as prepubertal, peri-pubertal, or post-pubertal. "No signs of puberty" were taken as pre-pubertal. Tanner stage 1 was coded pre-pubertal, stages 2-4 were coded peri-pubertal, and stage 5 was considered post-pubertal. Stage 5 in boys was based on a combination of testicular size, pubic hair, and genitalia stage. When staging was not available, girls at least two years post-menarche were coded as post-pubertal (stage 5).

Peripheral bone mineral density (pDXA) at the right os calcis (BMDoc) was measured in a region of interest (ROI)

\footnotetext{
Abbreviations: $B M D$, bone mineral density; $D X A$, dual energy $x$ ray absorptiometry; OC, os calcis; PA, physical activity; pDXA, peripheral dual energy $x$ ray absorptiometry; PIXI, peripheral instantaneous $x$ ray
} imaging densitometer (Lunar); ROI, region of interest 


\section{What is already known on this topic}

- A measurement of BMD os calcis (BMDoc) can be used in adults for predicting fracture risk

- Lack of reference data adds to the uncertainty of how such measures should be used in paediatric practice

using a Lunar PIXI (peripheral instantaneous $x$ ray imaging) densitometer. The BMDoc was re-measured about 30 minutes later in a subgroup of 53 consecutive children to assess precision. Total bone mineral content and density were measured by a Lunar pencil beam DPX-L scanner (version 4.6) using the appropriate software depending on child size, as recommended by the manufacturer. The effective radiation dose for the whole body scan was about $0.02 \mu \mathrm{Sv}$ and was about a tenth of this for the peripheral scan.

Data were analysed using SPSS $^{26}$ with simple linear and stepwise multiple regression analyses and analysis of covariance. In analyses of the effects of physical activity and fracture history, the data of boys and girls were expressed as a height adjusted Z-score ([observed value present reference value]/residual standard deviation of the reference equation derived from the present study). Comparison of means was by $t$ test or one way analysis of variance. The $5 \%$ level was accepted as indicating statistical significance.

The study was approved by the South Tees Acute Hospitals NHS Trust research ethics committee.

\section{RESULTS}

A total of 403 children were seen, but data from 28 were discarded; 24 children had pDXA or total body scans that were technically unsatisfactory, three children were nonCaucasian, and one child had a growth disorder. Hence, complete data were obtained on 375 children (218 girls and 157 boys). Of these, 47 girls (22\%) and 34 boys (22\%) had a history of fracture. A preliminary analysis showed that the BMDoc adjusted for body size was reduced significantly in these children compared with children with no history of fracture, so they were excluded from the analysis to derive reference equations.

Eleven per cent of girls $(n=19)$ and $16 \%$ of boys $(n=20)$ were being treated for asthma, but none were taking oral

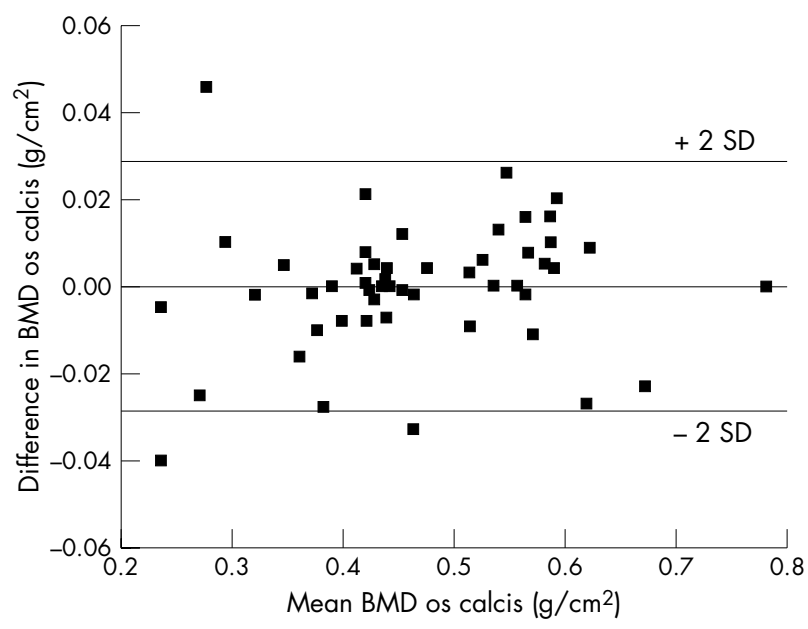

Figure 1 Bland-Altman plot of the difference between repeat measures of BMD os calcis in 53 children.

\section{What this study adds}

- BMDOc can be measured easily and simply by pDXA in children and has a reproducibility equivalent to that of adults

- In children aged 5-18 years BMDOC is strongly related to total BMD and can be predicted with reasonable accuracy using a proportional model based on height alone

- $B M D O C$ in girls may peak at about age 15 years

- BMDOC is greater in those children who report higher levels of habitual physical activity

steroids or had taken oral steroids in the six months before the scan; the preliminary analysis did not reveal a difference in BMDoc related to asthma treatment.

In the repeatability study BMDoc was measured twice on 53 children. The mean and SD of the difference between measures was 0.0001 and $0.015 \mathrm{~g} / \mathrm{cm}^{2}$; the $95 \%$ limits of agreement between repeat measures were -0.029 to $+0.029 \mathrm{~g} / \mathrm{cm}^{2}$. The difference was unrelated to mean BMDoc of the two measures (Bland-Altman plot, ${ }^{27}$ fig 1 ).

Table I presents mean and SD for age, and anthropometry and densitometry data of the reference population. On average, the children were taller and heavier than the national reference data compiled in $1990 .{ }^{24}$

The distribution of the BMDoc was parametric. BMDoc was related positively to age, height, and total BMD (table 2). When matched for height the difference in mean BMDoc between boys and girls was minimal in young children, but increased with age at and beyond puberty. The Pearson correlation coefficients of BMDoc for age, height, and total BMD were $0.78,0.78$, and 0.82 in girls, and $0.85,0.87$, and 0.88 in boys $(\mathrm{p}<0.001$ in all cases $)$. In boys and girls BMDoc was linearly related to body mass index (body mass $/$ height $^{2}$ ) $(\mathrm{p}<0.001)$, but the correlation coefficients were weaker (0.64 in girls and 0.63 in boys).

\section{Reference values for BMD os calcis}

Mean BMDoc appeared to plateau at about age 15 in girls, but not in boys (table 2). The variability in BMDoc increased with increasing age and height (table 2) and was

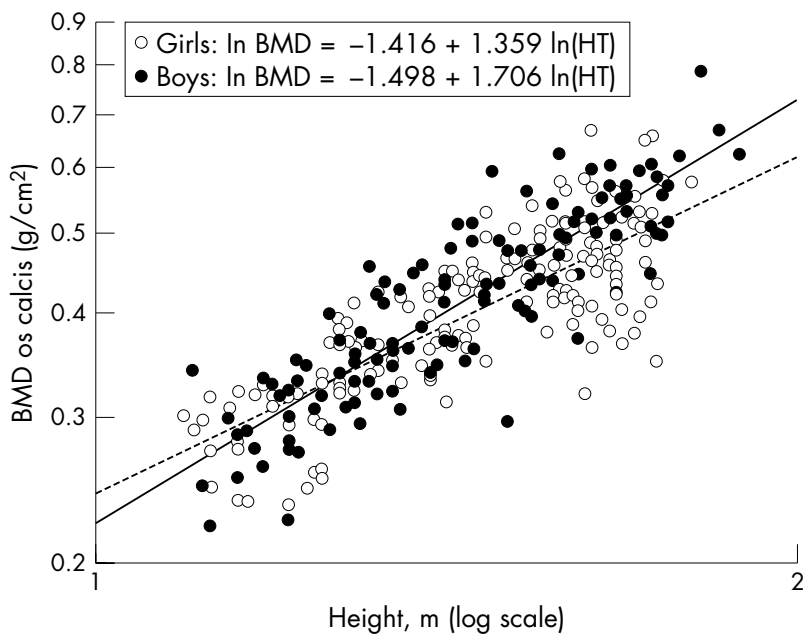

Figure 2 Relation of $\ln (B M D$ os calcis) with $\ln$ (height) in boys (closed circles, solid line) and girls (open circles, dashed line). 
Table 1 Descriptive statistics for age, anthropometry, and densitometry data by sex

\begin{tabular}{|c|c|c|c|c|c|}
\hline & Units & Mean & SD & Minimum & Maximum \\
\hline \multicolumn{6}{|l|}{ Girls $(n=171)$} \\
\hline Age & years & 11.5 & 3.5 & 5.0 & 18.6 \\
\hline Height & $\mathrm{cm}$ & 146.8 & 19.0 & 109 & 180 \\
\hline Z-score height* & - & 0.36 & 0.94 & -1.98 & 2.84 \\
\hline Body mass & $\mathrm{kg}$ & 42.2 & 15.6 & 18 & 96 \\
\hline Z-score body mass* & - & 0.30 & 0.93 & -1.81 & 3.10 \\
\hline Total BMD & $\mathrm{g} / \mathrm{cm}^{2}$ & 0.96 & 0.13 & 0.73 & 1.25 \\
\hline Total BMC & g & 1562 & 597 & 636 & 2980 \\
\hline Total Area & $\mathrm{cm}^{2}$ & 1569 & 415 & 847 & 2490 \\
\hline BMDOC & $\mathrm{g} / \mathrm{cm}^{2}$ & 0.414 & 0.091 & 0.23 & 0.67 \\
\hline \multicolumn{6}{|l|}{ Boys ( $n=123$ ) } \\
\hline Age & years & 10.6 & 3.1 & 5.1 & 16.3 \\
\hline Height & $\mathrm{cm}$ & 144.6 & 19.4 & 110 & 189 \\
\hline Z-score height* & - & 0.42 & 0.90 & -1.81 & 2.72 \\
\hline Body mass & $\mathrm{kg}$ & 39.5 & 16.1 & 17 & 98 \\
\hline Z-score body mass* & - & 0.49 & 0.92 & -1.60 & 2.96 \\
\hline Total BMD & $\mathrm{g} / \mathrm{cm}^{2}$ & 0.94 & 0.12 & 0.76 & 1.30 \\
\hline Total BMC & g & 1530 & 621 & 671 & 3558 \\
\hline Total Area & $\mathrm{cm}^{2}$ & 1566 & 439 & 869 & 2751 \\
\hline BMDOC & $\mathrm{g} / \mathrm{cm}^{2}$ & 0.427 & 0.110 & 0.22 & 0.78 \\
\hline
\end{tabular}

proportional to its absolute value. A power relation to height $\left(\right.$ BMDoc $=\mathrm{a} \times\left(\right.$ height $\left.^{\mathrm{b}}\right)$, or $\ln ($ BMDoc $)=\ln (\mathrm{a})+\mathrm{b} \times \ln ($ height $\left.)\right)$ explained more variance than either a linear, logarithmic, or quadratic model. However, the slope of the relation between $\ln$ BMDoc and $\ln$ height was significantly different between boys and girls $(p=0.003$, fig 2$)$. Accordingly, sex specific equations were derived (table 3 ). The residuals were normally distributed and were unrelated to age (Pearson correlation coefficients not significantly different from zero, $\mathrm{p}>0.05)$ but were weakly related to body mass in girls $(r=0.16, \mathrm{p}=0.04)$ and to BMI in both sexes (girls: $r=0.32, \mathrm{p}<0.001$; boys: $r=0.24, \mathrm{p}=0.007$ ). However, BMI was not independent of height $(r=0.56$ in girls, $r=0.58$ in boys, $\mathrm{p}<0.001)$. Figures 3 and 4 show centile charts for BMDoc based on height alone.

\section{Effect of habitual physical activity level on BMD os calcis}

Data on weekly activity level were available for 287 children without a history of fracture. The BMDoc expressed as a height adjusted Z-score (see methods) was related positively to the level of physical activity (PA) outside school (table 4). The average difference between doing little or no exercise outside school and doing sports or physical activity regularly for $>5$ hours per week was equivalent to a BMDoc height adjusted Z-score of about 0.6 units in boys and girls. This approximated to about $0.03 \mathrm{~g} / \mathrm{cm}^{2}$ in both sexes.

\section{Effect of a history of fracture on BMD os calcis}

A history of fracture was associated with a significantly reduced BMDoc compared with that predicted in boys (mean

\begin{tabular}{|c|c|c|c|c|c|c|c|}
\hline \multirow[b]{2}{*}{ Age } & \multirow[b]{2}{*}{$\mathbf{n}$} & \multicolumn{2}{|c|}{ Height $(\mathrm{cm})$} & \multicolumn{2}{|c|}{ BMD os calcis $\left(\mathrm{g} / \mathrm{cm}^{2}\right)$} & \multicolumn{2}{|c|}{ Total BMD $\left(\mathrm{g} / \mathrm{cm}^{2}\right)$} \\
\hline & & Mean & SD & Mean & SD & Mean & SD \\
\hline \multicolumn{8}{|l|}{ Girls } \\
\hline $5-6$ & 8 & 113.2 & 4.3 & 0.294 & 0.024 & 0.816 & 0.035 \\
\hline $6-7$ & 12 & 119.3 & 3.9 & 0.287 & 0.032 & 0.828 & 0.047 \\
\hline $7-8$ & 20 & 124.9 & 4.7 & 0.328 & 0.053 & 0.842 & 0.054 \\
\hline $8-9$ & 11 & 131.2 & 5.9 & 0.351 & 0.025 & 0.854 & 0.034 \\
\hline $9-10$ & 11 & 137.4 & 3.8 & 0.381 & 0.044 & 0.872 & 0.057 \\
\hline 10-11 & 15 & 141.1 & 6.6 & 0.402 & 0.043 & 0.896 & 0.032 \\
\hline $11-12$ & 12 & 150.8 & 7.7 & 0.443 & 0.051 & 0.943 & 0.034 \\
\hline $12-13$ & 12 & 157.3 & 8.4 & 0.440 & 0.068 & 0.980 & 0.057 \\
\hline $13-14$ & 14 & 159.1 & 7.5 & 0.458 & 0.048 & 1.022 & 0.067 \\
\hline $14-15$ & 20 & 162.4 & 5.3 & 0.480 & 0.071 & 1.084 & 0.069 \\
\hline $15-16$ & 21 & 166.3 & 6.7 & 0.478 & 0.054 & 1.093 & 0.067 \\
\hline $16-17$ & 7 & 169.0 & 4.1 & 0.544 & 0.098 & 1.156 & 0.070 \\
\hline $17-18$ & 8 & 168.1 & 5.6 & 0.489 & 0.102 & 1.147 & 0.065 \\
\hline \multicolumn{8}{|l|}{ Boys } \\
\hline $5-6$ & 10 & 115.2 & 3.8 & 0.288 & 0.041 & 0.821 & 0.030 \\
\hline $6-7$ & 12 & 122.9 & 3.8 & 0.307 & 0.034 & 0.838 & 0.022 \\
\hline $7-8$ & 8 & 127.6 & 5.7 & 0.331 & 0.041 & 0.890 & 0.046 \\
\hline $8-9$ & 13 & 130.0 & 5.3 & 0.356 & 0.054 & 0.864 & 0.054 \\
\hline $9-10$ & 12 & 137.6 & 5.9 & 0.384 & 0.055 & 0.888 & 0.055 \\
\hline $10-11$ & 12 & 143.3 & 9.0 & 0.431 & 0.059 & 0.951 & 0.064 \\
\hline $11-12$ & 10 & 149.7 & 6.4 & 0.454 & 0.040 & 0.936 & 0.057 \\
\hline $12-13$ & 15 & 156.4 & 6.5 & 0.493 & 0.087 & 0.985 & 0.066 \\
\hline $13-14$ & 12 & 164.0 & 6.6 & 0.519 & 0.064 & 1.034 & 0.081 \\
\hline $14-15$ & 9 & 167.9 & 11.3 & 0.540 & 0.068 & 1.102 & 0.101 \\
\hline $15-17$ & 10 & 175.0 & 7.0 & 0.588 & 0.082 & 1.149 & 0.078 \\
\hline
\end{tabular}




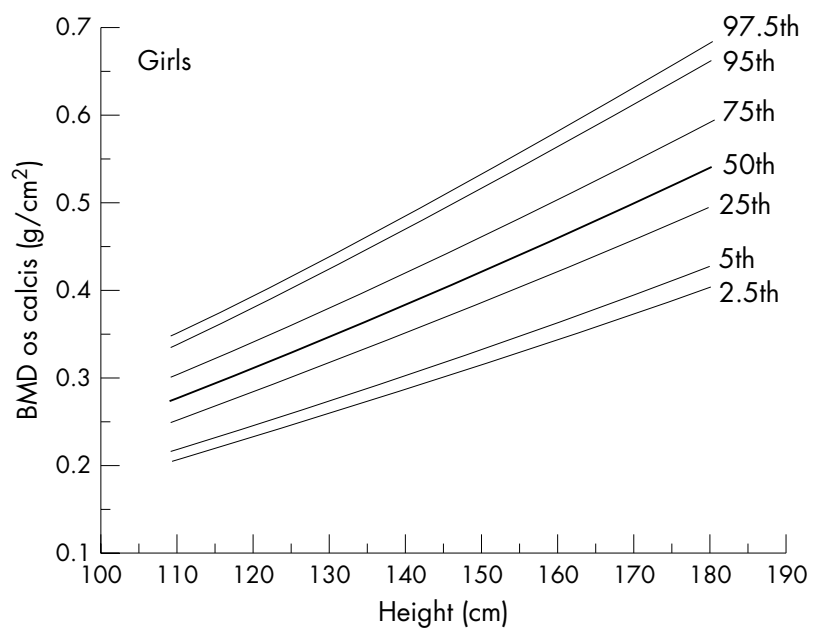

Figure 3 Centile chart for predicting BMD os calcis in girls.

height adjusted Z-score $=-0.52,95 \% \mathrm{CI}-0.86$ to $-0.17, \mathrm{p}=$ 0.005 ) but not in girls (mean height adjusted Z-score $=0.19$, $95 \%$ CI -0.08 to $0.46, p=0.16$ ). The reduced BMDoc in boys was not a consequence of short stature (fig 5) and amounted to about $0.03 \mathrm{~g} / \mathrm{cm}^{2}$ or about $7 \%$ of the mean.

\section{Effect of pubertal stage on BMD os calcis}

An estimate of pubertal stage was possible in all the girls and in 114 (93\%) of the boys. The BMDoc expressed as a height adjusted Z-score was unrelated to stage of puberty in either boys $(F=0.02, p=0.97)$ or girls $(F=0.6, p=0.53)$.

\section{DISCUSSION}

\section{Statement of principal findings}

Bone density measured at the os calcis is easily measured in children and has a reproducibility equivalent to that in adults for which the standard deviation of repeated measures is about $0.010 \mathrm{~g} / \mathrm{cm}^{2}$ (manufacturer's literature). The procedure takes less than a minute and is suitable for most children aged 5 and above with no need to immobilise the child for 10-15 minutes as may be required for axial scanning. Technical difficulties obtaining os calcis measurements were encountered in nine children who had feet too small for the software to locate a "region of interest". But, in the main, where there were problems with obtaining scan data, this was usually with the whole body scan and arose from the inability of some children to remain still for a prolonged period.

The BMDoc is linearly and strongly related to total BMD and to body size in children aged $5-18$ years of age. Over this range the BMDoc of boys continues to increase with age, but that in girls appears to plateau at about age 15, attaining average values of about $0.49 \mathrm{~g} / \mathrm{cm}^{2}$ that concur with those in a local population of women in their third decade. ${ }^{28}$ Bone density at axial sites appears to peak in the third decade, and this difference in expectation may relate to the principal

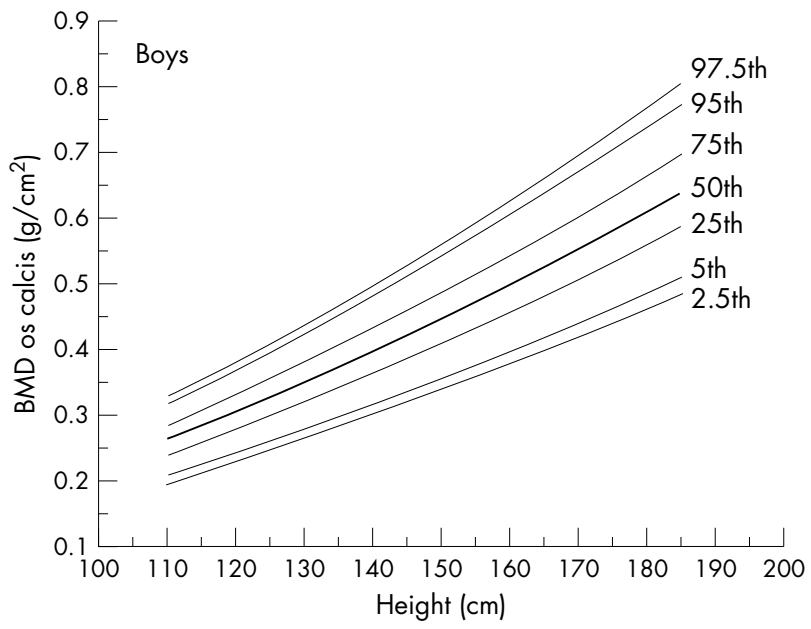

Figure 4 Centile chart for predicting BMD os calcis in boys.

component of the os calcis being cancellous rather than cortical bone.

The BMDoc can be described with reasonable accuracy using a power relation with height. Use of additional terms such as BMI could have improved the accuracy of the prediction equation by about $4 \%$ in girls and $2 \%$ in boys, but in this study, BMI was not independent of height. Furthermore, BMI may be affected clinically in nutritional disorders, so, for these reasons, may not be considered an appropriate reference variable suitable for all circumstances.

In boys and girls BMDoc is related positively to habitual physical activity when expressed as a simple three point score. BMDoc was marginally less in boys, but not in girls with a history of fracture.

\section{Strengths and weaknesses of the study}

We are not aware of similar, published studies reporting reference data for BMDoc in childhood. The present study was cross-sectional and subjects were self-selected, being recruited from the community. They were not chosen at random from the population. Hence, the relations we describe may not be representative of the general population of healthy Caucasian children. A further limitation was that pubertal status, physical activity level, and history of fracture were self-reported. In particular, we did not ask about type of exercise undertaken, and although we asked about fracture site we did not collect data on the age at fracture or on its nature (for example, low trauma). Furthermore, we acknowledge that our study was not powered for determining the effect of fracture history on the BMDoc, so the negative finding in girls may have been attributed to a type II error (false negative), or the positive finding in boys to a type I error (false positive).

Whole body DXA scanning has been used in studies of healthy children. ${ }^{5}{ }^{14} 15$ Our findings using pDXA have shown correlations between BMDoc and age, height, and body mass,

\begin{tabular}{|c|c|c|c|}
\hline & & $\mathbf{R}^{2}$ & $\begin{array}{l}\text { Coefficient of variation } \\
\text { (\%) }\end{array}$ \\
\hline Girls & BMDOC $\left(\mathrm{g} / \mathrm{cm}^{2}\right)=0.242 \times(\text { height, } \mathrm{m})^{1.359}$ & 64.8 & 13.3 \\
\hline Boys & BMDOc $\left(\mathrm{g} / \mathrm{cm}^{2}\right)=0.223 \times(\text { height, } \mathrm{m})^{1.706}$ & 76.8 & 12.6 \\
\hline
\end{tabular}


Table 4 Habitual physical activity and BMD os calcis by sex

\begin{tabular}{|c|c|c|c|c|}
\hline & \multicolumn{2}{|c|}{ Boys } & \multicolumn{2}{|c|}{ Girls } \\
\hline & $\mathrm{n}$ & BMD os calcis (Z-scores) & $n$ & BMD os calcis (Z-scores) \\
\hline $\begin{array}{l}\text { Little or no activity outside school } \\
\text { Sports or PA at least } 3 \text { hours per week } \\
\text { Sports regularly, }>5 \text { hours per week } \\
\text { F statistic (p) }\end{array}$ & $\begin{array}{l}22 \\
39 \\
57\end{array}$ & $\begin{array}{l}-0.42(-0.83 \text { to }-0.02) \\
0.19(-0.13 \text { to } 0.52) \\
0.19(-0.08 \text { to } 0.45) \\
3.4(0.036)\end{array}$ & $\begin{array}{l}34 \\
72 \\
63\end{array}$ & $\begin{array}{l}-0.25(-0.56 \text { to } 0.06) \\
0.05(-0.15 \text { to } 0.25) \\
0.32(0.04 \text { to } 0.61) \\
3.9(0.021)\end{array}$ \\
\hline
\end{tabular}

which are similar to those among BMD measured at axial sites.

We found a graded response in BMDoc with levels of regular physical activity. This effect was seen in boys as well as girls. A dose-response relation between physical activity measured in minutes/week and age adjusted BMD at the lumbar spine and total body has been observed in boys, but not in girls. ${ }^{3}$ Type of exercise and timing with respect to sexual maturation is important. ${ }^{4}$ Bone mass at the hip and spine can be increased by a short programme of regular daily jumping, ${ }^{7}$ and the effects appear to be maintained at least for the hip at 7 months post-intervention. ${ }^{8}$ A cross-sectional study of young female gymnasts and runners reported increased calcaneal quantitative ultrasound measurements compared with controls. ${ }^{29}$

\section{Implications for clinicians and policy makers}

The portability of the pDXA scanner, speed of scan, and low radiation dose makes it an ideal instrument for use in either clinical studies or in field studies monitoring, for example, changes in bone density associated with sports activities. The present normative centile charts for BMDoc may be used by clinicians in managing patients, particularly where there is no access, or only limited access to axial scanners. The BMDoc should not be used for diagnosis, but could be used for monitoring children taking drugs with a potential effect on bone mineral accretion, such as anticonvulsants and corticosteroids. ${ }^{10}{ }^{11}$ However, the evidence that the os calcis is an appropriate site for this role has yet to be established. The more likely role for pDXA would be investigation of children at risk of low bone mass, including conditions such as malabsorption syndromes. ${ }^{16}$

A reduced bone density in childhood appears to be associated with an increase in fracture risk, ${ }^{30} 31$ as it is in

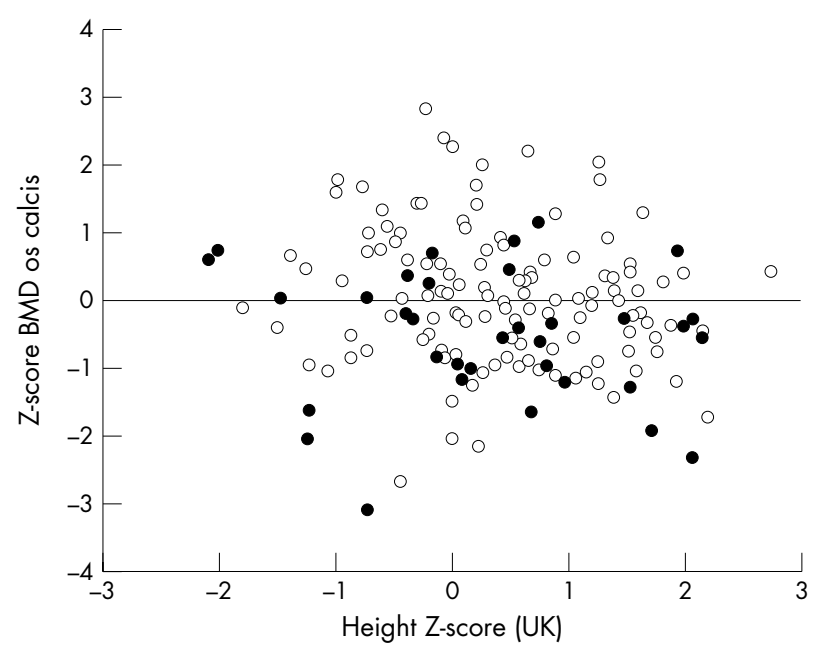

Figure 5 Z-score BMD os calcis in boys with (closed circles) and without (open circles) a history of fracture plotted against height expressed as a Z-score using UK reference data. ${ }^{24}$ adulthood. In practice, the incidence of fractures in childhood is low and maximal in the early teens. In osteogenesis imperfecta they may occur, depending on the particular subtype, in fetal life, early infantile life, or throughout infancy. Although criteria for the diagnosis of osteoporosis and osteopenia are well established in adults, ${ }^{32}$ the criteria for defining these states in children are not established, and age related Z-scores are usually employed. Measurement of total body BMD has shown that every standard deviation decline in BMD is associated with a doubling of risk of fractures in girls, ${ }^{31}$ a risk similar to that seen in adult women.

The relation between fracture risk and BMDoc warrants investigation. However, the main importance of defining bone mass attainment in children may be as a predictor of peak bone density for which studies have shown that BMD of adolescents "tracks" into adulthood. ${ }^{33}$ This evidence of tracking is encouraging, though the follow up of axial bone density in young children can be compromised by use of different, size related software as the child grows. ${ }^{12}$ This restriction does not apply to the peripheral scanner which uses one set of software for children and adults. However, prospective studies describing the longitudinal change in the BMDoc are required before recommending use of this measure as a screening tool for poor bone mineral attainment.

As a guide to use in clinical practice, we suggest that a child's height should be assessed for biological age (if available), then the BMDoc compared to that predicted from its relation with height. A low BMDoc relative to predicted may indicate a low total BMD and need for axial scanning.

\section{Unanswered questions and future research}

The observation that girls of 15 or more appear to reach levels of BMDoc similar to those found in women aged 20-30 suggests that BMDoc may peak in the late teens. This is in keeping with one study of BMD of the total body, lumbar spine, and femoral neck, ${ }^{13}$ but at variance with the observation of Hadjidakis and colleagues ${ }^{34}$ who suggested that BMDoc in women peaked in the third decade, although they did not measure BMD in women younger that 20. If confirmed by longitudinal study, this observation could justify use of the portable equipment to screen girls in their last year at school to identify those with reduced bone density. ${ }^{35}$ This may be of particular value when targeted at girls with a maternal family history of bone disorders or fractures.

In summary, BMDoc can be measured simply and easily in children using a portable pDXA scanner. Normative data have been established based on height. The reference charts can be used in clinical practice, in screening for reduced bone density in childhood, and in further research. The equipment has particular merit for use in field studies.

\section{ACKNOWLEDGEMENTS}

We thank the children and parents for their time, the local Teesside Osteoporosis Group for some funding, and Dr AH Al-Shirawi for help with data collection. 


\section{Authors' affiliations}

J N Fordham, M S Kibirige, J Venables, J Bates, O Pitcher, Departments of Rheumatology and Paediatrics, The James Cook University Hospital, Middlesbrough, UK

D J Chinn, Centre for Primary and Community Care, University of Sunderland, UK

N J Crabtree, Department of Nuclear Medicine, Queen Elizabeth Hospital, Birmingham, UK

\section{REFERENCES}

1 Gilsanz V, Skaggs, DL, Kovanlikaya A, et al. Differential effect of race on the axial and appendicular skeletons of children. J Clin Endocrinol Metabol 1998;83:1420-7.

2 Jones G, Dwyer T. Birth weight, birth length, and bone density in prepubertal children: evidence for an association that may be mediated by genetic factors. Calcif Tissue Int 2000;67:304-8.

3 Boot AM, de Ridder MAJ, Pols HAP, et al. Bone mineral density in children and adolescents: relation to puberty, calcium intake, and physical activity. $J$ Clin Endocrinol Metabol 1997;82:57-62.

4 Slemenda CW, Reister TK, Hui SL, et al. Influences on skeletal mineralisation in children and adolescents: evidence for varying effects of sexual maturation and physical activity. I Pediatr 1994;125:201-7.

5 Kroger $\mathbf{H}$, Kotaniemi A, Vainio $P$, et al. Bone densitometry of the spine and femur in children by dual-energy $\mathrm{x}$ ray absorptiometry. Bone Miner 1992; 17:75-85.

6 Martin AD, Bailey DA, Mckay HA, et al. Bone mineral and calcium accretion during puberty. Am J Clin Nutr 1997;66:611-15.

7 Fuchs RK, Bauer JJ, Snow CM. Jumping improves hip and lumbar spine bone mass in prepubescent children: a randomised controlled trial. J Bone Miner Res 2001;16:148-56.

8 Fuchs RK, Snow CM. Gains in hip bone mass from high-impact training are maintained: a randomised controlled trial in children. J Pediatr 2002;141:357-62.

9 Specker BC, Beck A, Kalwarf $M$, et al. Randomised trial of varying mineral intake on total bone mineral accretion during the first year of life. Paediatrics 1997;99:E12.

10 Boot AM, de Jongste JC, Verberne AA, et al. Bone mineral density and bone metabolism of prepubertal children with asthma after long-term treatment with inhaled corticosteroids. Pediatr Pulmonol 1997;24:379-84.

11 Boot AM, Bouquet J, Krenning EP, et al. Bone mineral density and nutritional status in children with chronic inflammatory bowel disease. Gut 1998;42:188-94

12 Fewtrell MS, on behalf of the British Paediatric and Adolescent Bone Group. Bone densitometry in children assessed by dual $\mathrm{x}$ ray absorptiometry: uses and piffalls. Arch Dis Child 2003;88:795-8.

13 Lu PW, Briody JN, Ogle GD, et al. Bone mineral density of total body, spine and femoral neck in children and young adults: a cross-sectional and longitudinal study. J Bone Miner Res 1994:9:1451-8.

14 Molgaard C, Thomsen BL, Prentice A, et al. Whole body bone mineral content in healthy children and adolescents. Arch Dis Child 1997;76:9-15.

15 Van der Sluis IM, de Ridder MAJ, Boot AM, et al. Reference data for bone density and body composition measured with dual energy $\mathrm{x}$ ray absorptiometry in white children and young adults. Arch Dis Child 2002;87:341-7.

16 van der Sluis IM, de Muinck Keizer-Schrama SMPF. Osteoporosis in childhood: bone density of children in health and disease. J Pediatr Endocrinol Metab 2001;14:817-32.

17 Fordham JN, Chinn DJ, Kumar N. Identification of women with reduced bone density at the lumbar spine and femoral neck using BMD at the os calcis. Osteoporosis International 2000;11:797-802.

18 Fordham JN, Chinn DJ, Bates J, et al. Identification of men with reduced bone density at the lumbar spine and femoral neck using BMD of the os calcis. J Clin Dens 2004;7:134-42.

19 Ross PD, Davis JW, Epstein RS, et al. Pre-existing fractures and bone mass predict vertebral fracture incidence in women. Ann Intern Med 1991;114:919-23.

20 Black DM, Cummings SR, Genant HK, et al. Axial and appendicular bone density predict fractures in older women. J Bone Miner Res 1992;7:633-8.

21 Ozonoff MB. Pediatric orthopedic radiology, 2nd edn. Philadelphia, PA: WB Saunders, 1992:780.

22 Faulkner KG, Gluer CC, Majumdar S, et al. Noninvasive measurements of bone mass, structure, and strength: current methods and experimental techniques. Am J Roentgenol 1991:157:1229-37.

23 National Osteoporosis Society. Position statement on the use of peripheral $x$ ray absorptiometry in the management of osteoporosis, National Osteoporosis Society, Bath, UK, November, 2001.

24 Freeman JV, Cole TJ, Chinn S, et al. Cross sectional stature and weight reference curves for the UK, 1990. Arch Dis Child 1995;73:17-24.

25 Tanner JM. Growth at adolescence, 2nd edn. Oxford: Blackwell Scientific, 1962.

26 SPSS. Statistical package for the social sciences, release 10.0. Chicago, IL: SPSS, 2000.

27 Bland JM, Altman DG. Statistical methods for assessing agreement between two methods of clinical measurement. Lancet 1986;i:307-10.

28 Cook A, Fordham JN, Chinn DJ, et al. Reference values for BMD os calcis in Caucasian women. Osteoporos Int 2001;12(suppl 2):S26-7.

29 Lehtonen-Veromaa M, Mottonen T, Nuotio I, et al. Influences of physical activity on ultrasound and dual-energy $\mathrm{X}$-ray absorptiometry bone measurements in peripubertal girls: a cross-sectional study. Calcif Tissue Int 2000;66:248-54.

30 Chan SM, Hess $M$, Hollis J, et al. Bone mineral studies in childhood accident fractures. Am J Dis Child 1984;138:569-70.

31 Goulding A, Jones IE, Taylor RW, et al. More broken bones: a 4 year double cohort study of young girls with and without distal forearm fractures. J Bone Miner Res 2000;15:2011-18.

32 WHO Study Group. Assessment of fracture risk and its application to screening for osteoporosis. Geneva: World Health Organisation, 1994

33 Matkovic V, Badenhop-Stevens N, Ha EJ, et al. Factors influencing peak bone mass. In: Burckhardt D, Dawson-Hughes B, Heaney RP, eds. Nutritional aspects of osteoporosis. San Diego, CA: Academic Press, 2001:11-22.

34 Hadjidakis D, Kokkinakis E, Giannopoulos G, et al. Bone mineral density of vertebrae, proximal femur and os calcis in normal Greek subjects as assessed by dual-energy $X$-ray absorptiometry: comparison with other populations. Eur J Clin Invest 1997;27:219-27.

35 Akisaka $M$, Zakouji $H$, Ariizumi $M$. A study of bone density and lifestyles of high school girls. Japanese Journal of Hygiene 1997;52:481-9. 